\title{
Diseño de un protocolo de enfermería para pacientes alérgicos al látex en nuestra unidad de hemodiálisis
}

\author{
Rubén Sierra Díaz - Lola Medina López - Ana Ciriza Aramburu
}

Centro de Diálisis Bellavista, Clínica San Carlos. Sevilla

\section{Sra. Directora:}

El látex es un producto vegetal procesado que gracias a sus propiedades elásticas, se utiliza para elaborar numerosos productos médicos y de uso cotidiano, como los guantes, globos y otros objetos ${ }^{1,2}$. La primera descripción de hipersensibilidad inmediata por látex se realizó en Alemania en $1927^{3}$, pero es a partir del año 1989 y coincidiendo con las recomendaciones internacionales para evitar el contagio del VIH cuando la alergia al látex se ha convertido en una verdadera epidemia con una morbimortalidad considerable.

Actualmente la alergia al látex constituye un problema sanitario importante existiendo un grupo de riesgo bien diferenciado constituido por niños con espina bífida 0 con anomalías urogenitales ${ }^{4}$ que requieren múltiples operaciones y cambio frecuente de sondas, por lo que el riesgo de desarrollar alergia al látex es mayor que el de la población general. No debemos olvidar que estos niños se convierten en pacientes potenciales de nuestros centros de diálisis. La alta prevalencia en determinados grupos de riesgo y la gravedad de las reacciones que puede producir (desde reacciones leves de contacto hasta shock anafiláctico), nos incitó a plantearnos como objetivo de estudio el realizar un protocolo de enfermería de aplicación en nuestro centro de hemodiálisis, para aquellos pacientes subjetivos de ser alérgicos al látex o diagnosticados de alergia al látex.

Correspondencia: ercoordi@hotmail.com
Se trata de un estudio descriptivo cuyo proceso se dividió en tres etapas diferenciadas. En una primera en la que nos preocupamos por obtener información sobre la alergia al látex, revisando publicaciones sobre el tema, poniéndonos en contacto con la Asociación Española de alérgicos a alimentos, con la Asociación Española de alérgicos al látex. Origen de esta revisión bibliográfica y documental pudimos conocer datos sobre epidemiología, grupos de riesgo, clínica, diagnóstico, tratamiento y prevención. Al mismo tiempo conseguimos: unos listados de productos y ambientes que pueden contener látex, de alimentos con reactividad cruzada al látex, de equipo y material sanitario para pacientes alérgicos al látex (tabla 1), de recomendaciones para medicamentos y hemoterapia y de aquellos materiales prohibido por contener látex frecuentemente y material alternativo.

\begin{tabular}{|c|c|c|}
\hline $\begin{array}{l}\text { OBJETOS QUE PUEDEN } \\
\text { CONTENER LÁTEX }\end{array}$ & $\begin{array}{l}\text { MATERIAL SANITARIO } \\
\text { RECOMENDADO PARA } \\
\text { PACIENTES ALÉRGICOS } \\
\text { AL LÁTEX }\end{array}$ & $\begin{array}{l}\text { ALIMENTOS CON } \\
\text { REACTIVIDAD CRUZADA } \\
\text { AL LÁTEX }\end{array}$ \\
\hline Vendajes de caucho & $\begin{array}{l}\text { Circuito respirador de } \\
\text { silicona de un solo uso }\end{array}$ & Plátano \\
\hline Preservativos & $\begin{array}{l}\text { Compresor silicona } \\
\text { Bandas de tela }\end{array}$ & Piña, aguacate \\
\hline $\begin{array}{l}\text { Material médico- } \\
\text { quirúrgico }\end{array}$ & $\begin{array}{l}\text { Electrodos de electro- } \\
\text { cardiograma: Skintact. }\end{array}$ & $\begin{array}{l}\text { Castaña, nuez } \\
\text { melón, melocotón }\end{array}$ \\
\hline $\begin{array}{l}\text { Diques de protección } \\
\text { dental usados en odon- } \\
\text { tología }\end{array}$ & $\begin{array}{l}\text { Guantes de caucho sinté- } \\
\text { tico: vinilo, nitrilo }\end{array}$ & Higo, kiwi, mango \\
\hline Suelas de calzado & $\begin{array}{l}\text { Tubo Guedel plástico } \\
\text { desechable transparente } \\
\text { o tubos de PVC }\end{array}$ & Maracuyá, papaya \\
\hline $\begin{array}{l}\text { Tetinas de biberón, } \\
\text { chupetes, muñecos }\end{array}$ & $\begin{array}{l}\text { Sistemas de infusión } \\
\text { doble con conexión en Y } \\
\text { sin látex }\end{array}$ & Uva, naranja \\
\hline
\end{tabular}

Tabla 1: Listado de productos que pueden contener látex, material sanitario recomendado para pacientes alérgicos al látex y alimentos con reactividad cruzada al látex 
La segunda fase de nuestro estudio consistió en la propia realización del protocolo de actuación, dirigido a proporcionar una adecuada atención sanitaria a los pacientes alérgicos al látex, evitando o minorizando su exposición, el algoritmo para la realización de este protocolo se muestra en la figura 1. Diferenciamos entre admisión del paciente, identificando posible grupo de riesgo y pacientes diagnosticados de alergia al látex y actuación de enfermería que contempla:

- Hora de realización de la sesión: se programará la sesión de hemodiálisis en el primer turno de la mañana, para evitar la exposición ambiental de partículas de látex que quedan en suspensión.

- Personal sanitario: durante el turno en que se dialice el paciente todo el personal sanitario que se encuentre en la sala deberá usar guantes libres de látex, como son nitrilo, vinilo, durapreno, etc. Al mismo tiempo se evitará entradas y salidas innecesarias del personal de las otras salas que estén usando guantes de látex. Se recomienda que en este último caso los guantes tengan bajo contenido proteico de látex y sin polvo: el polvillo de almidón de maíz que recubre los guantes contiene partículas de látex, aumenta el tamaño de las partículas y actúa como transporte para éstas.
- Material sanitario: al finalizar el turno anterior a la realización de la diálisis del paciente alérgico al látex, se procederá a forrar y proteger todo aquello que contenga látex (cables eléctricos y de monitores), a preparar material libre de látex como compresores, sustitución de paños desechables por paños de tela, líneas de diálisis libres de látex, sistemas de suero libres de tapón de caucho. Se utilizará para forrar vendaje circular de algodón de diferentes tamaños, cinta aislante y paños 0 sábanas de algodón.

- Medicación: se recomienda usar los envasados en ampollas y no viales. En caso de usar vial, quitar el tapón de goma para extraer el contenido, no pinchándolo nunca. En los casos donde se tengan que utilizar fármacos anestésicos, p.ej. para la colocación de catéteres, éstos serán de baja capacidad histaminoliberadora (lidocaína, etomidato, benzodicepinas), utilizándose el menor número de fármacos posibles y administrándose de forma lenta y diluida.

- Alimentación: los alimentos preparados en la clínica en el turno de diálisis del paciente alérgico o sensible de serlo al látex, serán manipulados con guantes ausentes de látex. Así mismo se evitarán todos aquellos alimentos con reactividad cruzada.

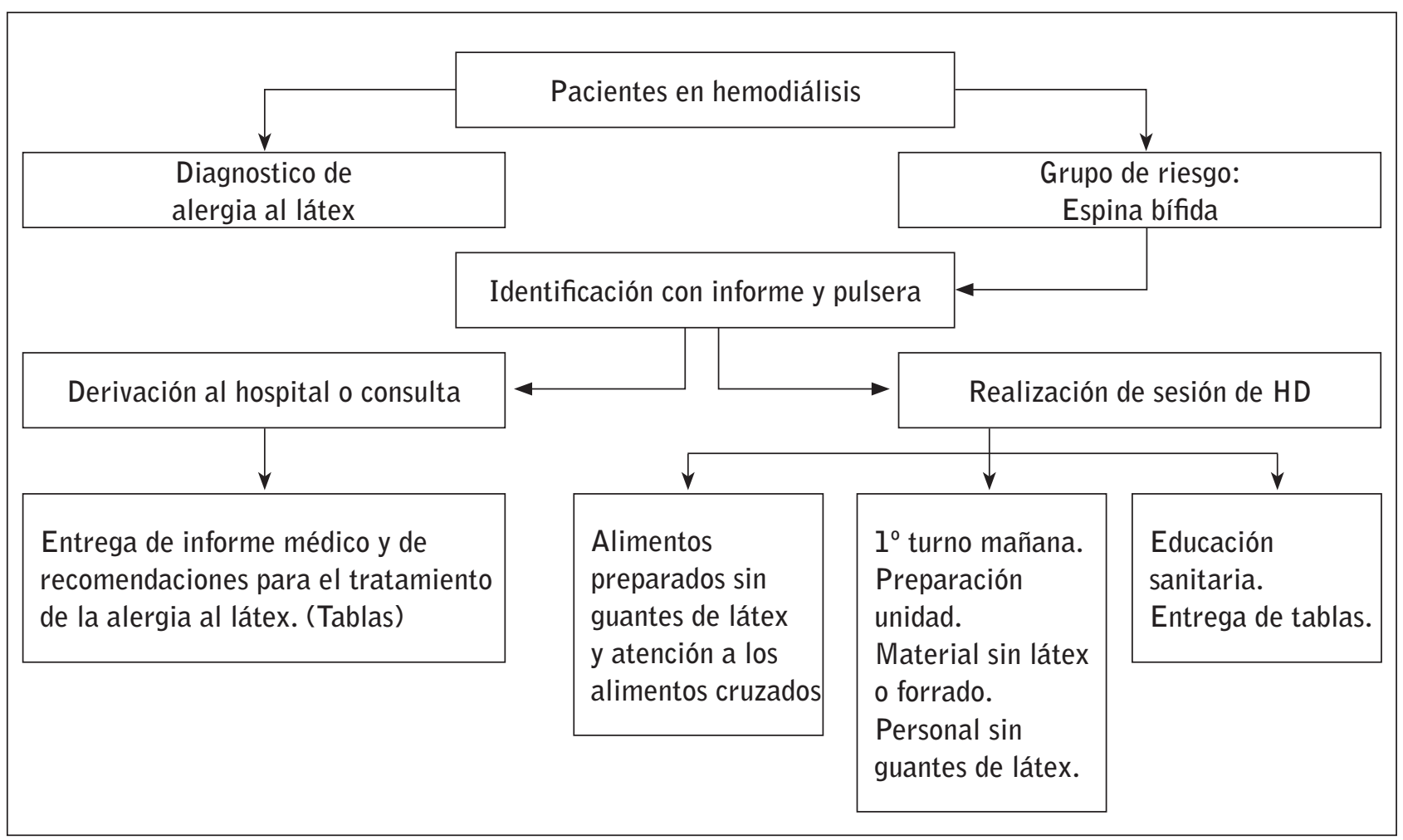

Figura 1: Algoritmo de protocolo de enfermería para pacientes alérgicos al látex 
- Educación sanitaria: basada en la explicación y entrega por parte de enfermería de una serie de tablas en la que aparecen objetos que pueden contener látex, alternativas a dichos materiales y listados de alimentos con reactividad cruzada al látex. Por otro lado, hacerles comprender la importancia de que vayan identificados con algún colgante para poder ser atendidos correctamente en caso de accidentes. En este sentido también se les informa de que existen recientes estu$\operatorname{dios}^{5}$ que demuestran que utilizando la inmunoterapia (vacunas) por vía subcutánea y sublingual, mejoran la sintomatología cutánea y respiratoria pudiendo los pacientes desensibilizados ser atendidos con guantes de látex y someterse a procedimientos diagnósticos y terapéuticos sin reaparición de los síntomas.

- Derivación a consultas o urgencias hospitalarias: cuando nuestros pacientes necesitan acudir al hospital u otros medios sanitarios derivados desde nuestro centro, les entregamos un informe dónde aparecen las recomendaciones generales para la prevención de alergia al látex así como material sanitario aconsejado (ausente de látex).

La última fase del proceso fue transmitir y concienciar al personal de nuestro centro de la importancia de la aplicación de este nuevo protocolo para el correcto tratamiento de los pacientes alérgicos al látex o grupo de riesgo. La prevención tiene un papel fundamental en los pacientes alérgicos al látex, pero dada la gran cantidad de material presente en los centros sanitarios es una tarea muy difícil. La alergia al látex abarca tanto el ámbito puramente de atención al paciente que se dializa como al de toma de decisiones (la compra de material o la organización de recursos para establecer áreas exentas de látex).

\section{Bibliografía}

1. Slater JE. Latex allergy. In: Kay AB,ed. Allergy and allergic diseases. Oxford: Blackwell Sciencie; 1997. 981-93.

2. Turjanmaa K,Alenius H, Mäkinen-Kiljunen S, Reunala T, Palosuo T. Natural rubber latex allergy. Allergy 1996; 51:593-602.

3. Stern G.Überempfindlichkeit gegen Kaustchuk als Ursache von Urticaria und quinckeschem odem. Klin Wochenscrift 1927; 6:1096-7.

4. Negro Alvarez JM et cols. Alergia al látex. Archivos de Alergia e inmunología Clínica 2003; 34;2;2835.

5. Patriarca G, Nucera E, Pollastrini E, et al. Sublingual desensitization: a new approach to látex allergy problem. Anesth Analg. 2002; 95(4):956-60. 